\title{
Social identity, status characteristics and social networks: Predictors of advice seeking in a manufacturing facility
}

\author{
Martin P. Copeland, ${ }^{1}$ Katherine J. Reynolds ${ }^{2}$ and Jamie B. Burton ${ }^{3}$ \\ ${ }^{1}$ School of Aeronautical, Civil and Mechanical Engineering, UNSW@ADFA, Australian Defence Force Academy, \\ ${ }^{2}$ School of Psychology, Australian National University, and ${ }^{3}$ People-Led Solutions Pty, Ltd, Canberra, Australia
}

In the sociological tradition, status characteristics and patterns of interpersonal relations within a social network are considered important in explaining organizational behaviour (e.g. influence, cooperation). In the social identity tradition, perceptions of shared psychological group membership and group prototypicality are considered important in explaining many of the same organizational behaviours. The present paper explores core variables within each of these perspectives as predictors of advice seeking among supervisors in a manufacturing facility. Dyadic measures of group assignment are found to better predict advice seeking than measures taken at the individual level. Identification with work groups predicted advice seeking from those perceived to be in the same group, and also from structural equivalents. Implications for theory and further research are discussed.

Key words: influence, organization, social identity, social network, status characteristics, structural equivalence.

\section{Introduction}

There is a long-standing and growing interest in the application of network ideas to the work organization (Ibarra \& Andrews, 1993; Shah, 1998; Borgatti \& Cross, 2003; Sparrowe \& Liden, 2005). To date, most organizational network research has been in what might loosely be described as the sociological, as opposed to the psychological, tradition of social psychology. In the psychological perspective, however, both Social Identity and Self-Categorization Theories (SIT/SCT, referred to jointly as the social identity perspective) are increasingly being applied to organizations (Hogg \& Terry, 2000; Haslam, 2001; Haslam \& Ellemers, 2005). The sociological perspective focuses on socially salient individual attributes and patterned connection between individuals as predictors of organizational behaviour (Wasserman \& Faust, 1994; Katz, Lazer, Arrow, \& Contractor, 2004). The social identity approach differs; here the focus is on perceived group memberships and social identification with groups. Despite calls for greater communication between sociological and psychological perspectives (Morgan \& Schwalbe, 1990; Stets \& Burke, 2000; Deaux \& Martin, 2003; Friedkin, 2004; McFarland \& Pals, 2005), there have been few attempts in this direction.

The difficulties with bridging sociological and psychological perspectives relate to their seemingly similar

Correspondence: Martin P. Copeland, School of Aeronautical, Civil and Mechanical Engineering, UNSW@ADFA, Australian Defence Force Academy, Canberra, ACT 2600, Australia. Email: m.copeland@adfa.edu.au

Received 27 July 2006; accepted 7 March 2007. domain of inquiry and terminology. In both fields, for example, there is discussion of similarity, cohesion, identity, roles, and social influence. While there might be much agreement between the sociological and psychological perspectives on factors that affect interpersonal dynamics (patterns of individual interaction, interpersonal networks, holding a common social position or certain social characteristics), this is not necessarily so in discussions around group processes and intergroup relations. A central differentiating point highlighted in this paper is group identification. In SIT/SCT, the focus is not just on individuals interacting with one another as individuals (interpersonal interactions and ties), but also on their interaction when psychologically identified as members of certain social groups (e.g. Turner \& Reynolds, 2001).

In the present study, links between psychological and sociological perspectives are investigated in a Social Network Analysis (SNA) of advice seeking in a manufacturing facility. Advice seeking is of interest because it relates to social influence, an area that has attracted much attention in both sociology and social psychology. It is assumed that if a person is willing to seek advice from someone, the advice giver is considered to be a legitimate, or valid, source of information in the organizational context. Advice givers, therefore, can reasonably be viewed as influential with respect to advice seekers. In examining the processes related to advice seeking, a range of measures are included that assess status characteristics (seniority, tenure, age), social network position (structural equivalence in the cooperation network) and psychological group variables (perceived work group membership, identification with work group, the degree to which work group members are considered typical, or prototypical, of the group). 
The present discussion focuses on the relationship between identification and a single network construct; structural equivalence. It should be acknowledged at the outset that structural equivalence is not the only, or necessarily the most important, network variable relevant to the processes investigated in this paper (and vice versa, see McFarland \& Pals, 2005). Prior to a discussion of specific hypotheses and SNA techniques, sociological (status characteristics, network structural equivalence) and psychological (SIT/SCT) perspectives on social influence are outlined.

\section{Status characteristics}

According to status characteristics theory, individuals possessing certain attributes, or characteristics, believed to be associated with greater competence are influential in shaping the attitudes and behaviours of others (Berger, Fisek, Norman, \& Zelditch, 1977). An individual's status characteristics often relate to technical expertise in a particular domain; however, more general attributes such as gender, education, occupation, class, and tenure can lead to expectations of competence across a wide range of social situations (Ridgeway, 2001). Within task groups, individuals come to share beliefs about the status value of specific and general attributes important for the task at hand. The distribution of valued attributes among group members leads to a status gradient, or rank ordering of status among group members. High-status members are more influential than low-status members and should be considered a valuable source of advice (Ridgeway \& Walker, 1995).

\section{Social identity}

Social identity and self-categorization theories (SIT/SCT) argue that one's own and others' location within a social system (society, organization) is important in determining social behaviour (Turner, 1982; Turner, Hogg, Oakes, Reicher, \& Wetherell, 1987; Turner, Oakes, Haslam, \& McGarty, 1994). The focus is on psychological groups rather than sociological or role groups. A person's selfdefinition, or self-categorization, as a member of a particular group is referred to as a social identity. An identity incorporates a person's 'knowledge that he [or she] belongs to certain groups together with some emotional and value significance to him [or her] of the group membership' (Tajfel, 1972, p. 31). In the organizational context, individuals can come to identify and act as members of distinct groups within the organization (e.g. marketing and sales), and as members of the organization as a whole (Haslam, 2001; Haslam, Eggins, \& Reynolds, 2003).

In the social identity perspective, individuals expect those they define as being similar (i.e. in the same group, or sharing a social identity) to understand relevant social stimuli in the same way as themselves. Because of the expectation for agreement, people categorized as being group members are viewed as valid sources of information and can be influential (Turner, 1991). Group members not only expect to agree, but actively seek agreement through mutual influence (Haslam, Turner, Oakes, McGarty, \& Reynolds, 1998). Not all group members are equally influential, however. Group members who best embody, or represent, the attitudes and behaviours that define the group (i.e. are prototypical of the group) have most influence within the group (Turner, 1991; Fielding \& Hogg, 1997). When seeking advice within the work group, individuals will tend to favour prototypical group members over those that are perceived to be less typical, or less representative, of the group.

The degree to which a person identifies with a group is a measure of the psychological significance of the group to the individual. ${ }^{1}$ Strength of identification depends upon a range of factors, for example, feeling valued and respected, sharing clear and agreed norms with other group members, and having a sense that one's group compares favourably with other groups (Dutton, Dukerich, \& Harquail, 1994; Tyler \& Blader, 2000). In an organizational context, there are usually at least two potential foci for identification - the work group and the organization as a whole (Reichers, 1985; Haslam et al., 2003; Cornelissen, Haslam, \& Balmer, 2007). Although most research has focused on identification and commitment to the organization as a whole, it is increasingly acknowledged that identification with one's work group is also relevant to work-related attitudes and behaviours (Ashforth \& Mael, 1989; van Knippenberg \& van Schie, 2000). There is also evidence supporting multiple identification dimensions (Hinkle, Taylor, FoxCardamone, \& Crook, 1989; Ellemers, Kortekaas, \& Ouwerkerk, 1999; Jackson, 2002). In the present study, evaluative, commitment and cognitive dimensions of identification with one's work group are measured and assessed as predictors of ingroup advice-seeking behaviour.

\section{Structural equivalence}

In the network tradition, empirical work has tended to be grounded in sociologically oriented, as opposed to psychologically oriented, theory (Monge \& Contractor, 2003; Tsai \& Kilduff, 2003; Katz et al., 2004). While psychological perspectives tend to view social position, or context, in terms of subjectively meaningful group memberships, the network approach views social position in terms of patterned social interaction (Brieger, 1976; Friedkin, 1984; Borgatti \& Everett, 1992; Rice, 1993).

The present study focuses on the degree to which individuals have similar cooperation ties to other individuals in the work place. Positional similarity arising from similar relations is usually referred to as structural equivalence (Wasserman \& Faust, 1994). In the strictest sense, two 
individuals are considered to be structurally equivalent when they have identical ties with other individuals in a network (Lorrain \& White, 1971). However, this definition can be relaxed, allowing a more general view of equivalence based on similar patterns of network ties (Burt, 1976). Salience of equivalents' opinions has been attributed to recognition 'that their normative, material and interpersonal circumstances in the social structure are similar' (Friedkin, 1993, p. 863), and also to competition in an organizational context (Burt, 1987). Those who have similar connections in the workplace are likely to compete for promotions and other benefits and are, therefore, likely to attend to one another's actions and opinions.

\section{Links between theoretical perspectives: Social identity and structural equivalence}

In terms of theory, social identity and structural equivalence may be viewed as distinct but related interpretations of the relationship between social position and social behaviour. Both perspectives assert that behaviour is related to social proximity (i.e. the degree to which individuals occupy a similar social position). Both theoretical traditions view individuals as being substitutable with respect to social structure to some extent, and neither perspective requires face-to-face interaction for influence to occur (Sailer, 1978; Turner et al., 1994). A major difference is that in the social identity perspective social position is defined with reference to identity-based groups, but in structural equivalence and other network perspectives social position is defined in terms of network structure (patterned and repeated interaction between individuals).

Although network and other sociological perspectives tend to view social context primarily in terms of structured interaction, the concomitant psychological processes are also important theoretically. Identity Theory (IT), for example, argues that individuals are linked to social structure through role identities that define socially appropriate behaviours (McCall \& Simmons, 1966; Stryker, 1980; Stryker \& Serpe, 1982). Role identities are shaped by a process of self-verification, or confirmation of views through interaction with individuals in counter-roles (Burke \& Stets, 1999). Feld's (1981) notion of a psychological 'focus' is somewhat analogous to the concept of social identity, incorporating psychological entities (e.g. 'neighbourhood' and 'work place') as both the antecedents and consequences of organized social interaction. In the network tradition, Galaskiewicz and Burt (1991) proposed a mechanism by which structural equivalents become normatively similar that involves group psychological processes. They argue, for example, that 'To affirm in-group membership and distance themselves from the out-group, individuals in structurally similar positions [structural equivalents] are expected to express similar perceptions and attitudes' (p. 89). It is possible, then, as in the small groups research tradition, for a social identity to emerge from repeated interpersonal interactions implicit in most organizational contexts.

It seems that social identity and network processes operate interdependently, and there is empirical evidence to support this view. McFarland and Pals (2005), for example, found that individuals in adolescent communities act to bring their social identity into alignment with network context. In organizations, structural equivalents show psychological effects that might be expected from identification with a work group, for example, mutual trust (Ferrin, Dirks, \& Shah, 2004), similar affective state (Totterdell, Wall, Holman, Diamond, \& Epitropaki, 2004), and norm contagion (Galaskiewicz \& Burt, 1991). Patterns of interaction that might be expected among structurally equivalent individuals have also been shown to lead to increased attraction to groups, group identification and group cohesion (Oakes, Haslam, Morrison, \& Grace, 1995; Fielding \& Hogg, 1997).

Given the links between perspectives, a potentially important question for both theorists and practitioners is the extent to which structural equivalents are also perceived to be members of the same work group. If structurally equivalent blocks and work groups are, in fact, separate structures it then becomes important to know whether significant behaviours such as advice seeking are related to perceived group membership, or to structural equivalence, or to both, as suggested by respective theories. A further question is whether identification with one's work group is positively associated with seeking advice from structural equivalents and, if so, whether the same type (i.e. dimension) of identification also predicts advice seeking within perceived work groups.

\section{Links between theoretical perspectives: Social identity and status characteristics}

The status characteristics perspective lends weight to overt individual status attributes as the paramount driver of competence expectations and, therefore, influence. The importance of status characteristics relative to group and network position remains unclear. There is evidence that perceived group membership (as opposed to prototypicality) and status characteristics are separate but additive predictors of influence (Kalkhoff \& Barnum, 2000; Oldmeadow, Platow, Foddy, \& Anderson, 2003). Other work in organizational contexts suggests that individual status characteristics are not particularly important in determining influence in organizations after the effects of network and physical proximity are controlled for (Ibarra \& Andrews, 1993; Shah, 1998; Borgatti \& Cross, 2003).

According to theory, both status characteristics and perceptions of prototypicality create an influence structure 
within a group. In fact, a status characteristic could be understood as an accepted status relation between members of a particular group. A question of some interest is whether prototypicality and status characteristics are separate predictors of advice seeking in an organization. To date, the combined effects of social identity (i.e. group membership, prototypicality and identification), network effects and status characteristics on influence have not been investigated. Evidence that work group prototypicality predicts advice after controlling for status would imply that individuals have at least some concept of the defining features of their work group, and value those qualities in addition to, or instead of, status characteristics (e.g. rank or tenure).

\section{The present research}

The investigation of psychological group processes among connected individuals is methodologically challenging. It is arguable that the methodological difficulties associated with non-independence have resulted in widespread reluctance to examine psychological processes in the context of social interaction (Haslam \& McGarty, 2001). The negative consequences of ignoring dependencies arising from social interconnection and methodological solutions to the nonindependence problem are discussed elsewhere (Kenny, Mannetti, Pierro, Livi, \& Kashy, 2002; McGarty \& Smithson, 2005).

Another issue arising in the study of social identity processes in connected individuals is the potential heterogeneity of subjectively defined groups and perceptions of prototypicality. Members within an organization may diverge in their understanding of who belongs to specific groups, and which individuals best represent those groups. Consensus regarding the membership of particular organizational groups and prototypicality may be expected to vary across situations (Haslam et al., 2003). The presence of conflict between management and employee groups, for example, may tend to increase consensus about group boundaries and prototypes for those groups. A strong brand and/or focus on an external competitor may also lead to stronger organizational identification and perceptions of prototypicality.

Despite potential variability in assessments of group membership, social identity variables are typically measured at the individual, or 'monadic', level. Individuals are usually asked about their own social identity on various dimensions, but not about their perceptions of others' social identity. Monadic measures do not directly address differing subjective assessments of group membership and prototypicality, which may be important in understanding processes of social influence within a group (Fielding \& Hogg, 1997; Turner \& Haslam, 2000). Two individuals might, for example, each assign themselves separately as belonging to the same group, but assign each other into different groups. Measured at the monadic level they have common group membership, but when both assessments are considered they are in different groups.

One alternative for dealing with heterogeneous perceptions of group membership in socially connected populations is to measure and analyze group variables as relational dyads. Fuzzy group boundaries and interdependence are assumed in SNA techniques (Katz et al., 2004) and, theoretically, there appears nothing to preclude the use of SNA in the investigation of influence and other effects arising from subjective assessments of group membership, prototypicality and other relevant variables. Network analysis of dyadic social identity variables is therefore advantageous in two respects. First, it overcomes the issue of statistical independence and second, it facilitates the investigation of group and network processes in a common analytical framework. This analysis extends previous work aimed at quantifying the association between social identities and network structure, for example McFarland and Pals (2005). Here we adopt a different methodology; dyadic measures of psychological group assignment and prototypicality are included in an organizational network analysis.

Based on the theoretical considerations outlined above, dyadic measures of perceived common group membership should better predict advice seeking than monadic measures of self-assigned group membership where heterogeneous perceptions of group membership are present (H1). Individuals should seek advice from others if they are structurally equivalent on a relevant dimension within the network social structure (H2) and/or if they perceive the other to be a member of the same work group as themselves (H3). Individuals should seek advice from those having high status within the work group (H4) and/or those they perceive to be prototypical of the work group they assign themselves to (H5). Individuals who identify with their work group should be more inclined to seek advice from those they perceive to be in the same group (H6). Finally, identification with work group should predict advice seeking from structural equivalents (H7).

\section{Methods}

\section{Participants and design}

The data were collected as part of a cultural survey commissioned by the manager of an industrial production facility. Participants were the top three levels of formal hierarchy within the facility. Data collection was conducted in two stages. First, interviews conducted with employees indicated there were five relevant groups within the plant centred on organizational functions (the particular group functions are not material to the present discussion). Although each participant held a formally designated rank 
within the organizational structure, they were not bound by rigid job specifications. Participants had considerable latitude in applying their expertise across the facility resulting in potential ambiguity as to their group membership.

Second, of the approximately 350 individuals employed at the factory, 56 supervisory staff members were invited to participate in the network study. Of the 56 invited, 49 responded giving a response rate of $87.5 \%$. Data were collected by means of a survey administered on site accompanied by a scripted verbal briefing on the content and purpose of the questionnaires.

Participants were asked whom they approached for advice and with whom they cooperated in the work place. A list of names was provided after each question and participants were asked to rate the strength of their advice seeking and cooperation ties with every person on the list that they knew. Participants were also asked to indicate which group they best belonged to (own group assignment) and the group they thought every person they knew belonged to (perception of other's group). The five groups contained 4 , 7, 9, 11 and 18 self-assigned respondents respectively, with 46 being male and three being female. Further, participants were asked how typical each person was of the attitudes and behaviours defining the group the participant assigned them to (prototypical). Individuals assigned themselves, and others, to the group they thought most appropriate, thereby specifying a dyadic measure of perceived group membership. In order to differentiate between missing responses and not knowing someone, participants were asked to cross out the names of people they did not know.

Participants completed three measures related to their own status (seniority, tenure and gender). Participants were also asked to rate their level of identification with the group they assigned themselves to. Given evidence supporting multiple identification dimensions (Hinkle et al., 1989; Ellemers et al., 1999; Jackson, 2002) a measure that included three factors of identification (cognitive, affect and commitment) was included (Cameron, 2004; Appendix I). ${ }^{2}$ The cognitive aspect of identification relates to 'its enduring (i.e. cross-situational) cognitive prominence within the overall structure of the self-concept' (p. 241). Cognitive identification is measured in terms of the frequency with which the group comes to mind and the importance of the group to self-definition. Ingroup affect addresses the evaluative component of group membership. Identification can have a positive or negative valence resulting in a positive or negative emotional response to group membership, and potentially high or low selfesteem. The third factor, ingroup commitment, concerns the degree to which group membership fosters a sense of belonging or emotional closeness to the group. Ingroup commitment relates to a sense of fitting in, having a sense of commitment to the group, and strong ties to other group members.

\section{Data treatment}

Data for all the variables were coded into $N \times N$ sociomatrices in which each entry $X i j$ equals the relation from actor $i$ to actor $j$, and $N$ equals the number of actors in the network (i.e. 49) (Wasserman \& Faust, 1994). For all relational variables, cases of actor $i$ not knowing actor $j$ (null tie) or not responding to the question (missing data) were coded as blank entry (empty cell). Matrices for measures of advice seeking, cooperation and prototypicality were created so that $X i j$ equals $i$ 's response for the relevant variable with respect to $j$.

Responses from the own group assignment question and the perception of other's group question were used to create monadic assignment and dyadic perception relational variables, respectively. For monadic assignment, if respondents $i$ and $j$ assigned themselves separately as belonging to the same group $X i j=1$ was entered into the matrix, otherwise $X i j=0$ was entered. For dyadic perception, if $i$ perceived (i.e. assigned) $j$ to be in the same group as him/herself $X i j=1$ was entered into the matrix, otherwise $X i j=0$ was entered. Null ties were entered as blank cells.

In other words, the monadic assignment variable captures information about respondents' self-assigned groups only, whereas the dyadic perception variable includes additional information about the group to which others were assigned by the respondent. The dyadic measure assesses the perceived membership of a particular group from a particular respondent's perspective, and it is therefore possible for each respondent to have a different view about which individuals belong to a given group. Groups defined by dyadic measures of perceived group membership need not correspond exactly to a particular group of people (i.e. a discrete set, or block, of individuals) in the organization. Dyadic measures of perceived group membership define social proximity, or similarity, with respect to work groups from each individual's subjective frame of reference.

Structural equivalence analysis using correlation as a measure of similarity was performed on the cooperation network using profile in UCINET 6 (Pattison, 1994; Wasserman \& Faust, 1994, p. 347; Borgatti, Everett, \& Freeman, 2002). Single-link clustering revealed that the most parsimonious solution included six structurally equivalent blocks with $2,4,4,5,16$ and 18 members. Individuals in the same structurally equivalent block share similar patterns of outwardly (who they cooperate with) and inwardly (who cooperates with them) directed cooperation ties. Structural equivalence blocks, therefore, define social proximity, or similarity, with respect to patterns of cooperative ties.

In order to allow identification with group to be entered into a matrix regression with relational variables, individual measures were entered into a matrix so that every entry in that person's row was coded with their identification score. 
A greater tendency for high identifiers to seek advice results in a relatively high correlation between identification and advice-seeking matrices.

Data for all three individual status measures were used to construct variables in matrix form. According to status characteristics theory, high status, rather than individual differences in status, leads to expectations of competence within work groups (Ridgeway \& Walker, 1995). Work group influence structures, and therefore advice seeking, are likely to be related to absolute rather than relative status. Accordingly, each respondent's score for seniority, tenure and gender were coded into every entry in their column. A greater tendency for high-status individuals to attract advice seeking will result in a relatively high correlation between the status attribute and advice-seeking matrix.

\section{Analysis}

Network correlation and multiple regression were used to investigate predictors of advice seeking. Because network data do not meet the assumption of independence required for ordinary least squares (OLS) tests of significance, quadratic assignment procedure (QAP) and multiple regression quadratic assignment procedures (MRQAP) in UCINET 6 were used to compute correlations and multiple regres-

Table 1 Statistics, scale reliabilities and correlations between variables

\begin{tabular}{lccc}
\hline & 1 & 2 & 3 \\
\hline 1 Affective identification & $(0.66)$ & & \\
2 Commitment & $0.60^{* *}$ & $(0.68)$ & \\
3 Cognitive identification & 0.18 & $0.33^{*}$ & $(0.72)$ \\
Mean & 4.90 & 4.40 & 3.79 \\
SD & 0.96 & 1.01 & 1.18 \\
\hline
\end{tabular}

$* p<0.05, * * p<0.01$.

Values in brackets are alpha coefficients. Responses were made on six-point scales. sions, respectively (Baker \& Hubert, 1981; Borgatti et al., 2002). QAP and MRQAP produce the same correlation and regression coefficients as OLS methods; however, a permutation technique is used to assess significance, thus avoiding the inflation of type 1 error rate associated with network autocorrelation (Krackhardt, 1988).

\section{Results}

\section{Identification scales}

Twelve items from Cameron's (2004) questionnaire were used for measuring identification with work group. Statistics, reliabilities and correlations are shown in Table $1 .{ }^{3}$ The mean level of identification was above the mid-point of the scale indicating that, overall, respondents identified with their self-assigned group.

\section{Heterogeneity}

The results indicated that heterogeneous perceptions of group membership were present, with the average number of groups attributed to each individual being nearly three $(M=2.90, S D=0.92)$. Table 2 shows the distribution of relations by same or different self-assigned group, perceived group membership and structurally equivalent block. There were 490 instances where one individual perceived another to be in the same group. Of those, there were 364 instances where individuals had also assigned themselves separately into the same group, and 126 instances where self-assigned groups differed (i.e. they were between individuals who assigned themselves into different groups), but at least one perceived a common group membership. Of the 505 cases where individuals assigned themselves to the same work group, there were 141 instances of individuals perceiving the other to be in a different group.

Individuals also varied in their perceptions of prototypicality, with the mean difference between maximum and minimum prototypicality attributed to a particular indi-

Table 2 Distribution of relations across self-assigned groups, perceived groups, and structurally equivalent blocks

\begin{tabular}{lcccc}
\hline & \multicolumn{2}{c}{ Dyadic perception } & & Structural equivalence \\
\cline { 2 - 5 } & $\begin{array}{c}\text { Same } \\
\text { perceived group }\end{array}$ & $\begin{array}{c}\text { Different } \\
\text { perceived group }\end{array}$ & $\begin{array}{r}\text { Same } \\
\text { block }\end{array}$ & $\begin{array}{r}\text { Different } \\
\text { block }\end{array}$ \\
\hline Monadic assignment & & & 141 & 214 \\
$\quad$ Same self-assigned group & 364 & 1390 & 369 & 1147 \\
$\quad$ Different self-assigned group & 126 & 331 & & 331 \\
Null or missing & & 2352 & & 2352 \\
Total & & & \\
\hline
\end{tabular}

$X i j$ and $X j i$ are counted as separate ties. 
vidual being close to three $(M=3.10, S D=0.51)$ on a five point scale. Variation in network proximity (geodesic distance) may account for heterogeneity in perceptions of group membership and prototypicality to some extent, with those more distant in the cooperation network being less certain of each other's group membership.

\section{Correlations between variables}

Table 3 shows correlations between the monadic assignment, dyadic perception, structural equivalence, prototypicality, cooperation, and advice seeking. Monadic assignment has the lowest correlation $(r=0.15, p<0.001)$ with advice seeking. The association between dyadic perception and advice seeking is stronger $(r=0.25, p<0.001)$ indicting that in the presence of heterogeneous perceptions of group membership, dyadic measures of group membership are stronger predictors of advice seeking than monadic measures (H1). Also in line with the social identity perspective (H5), the extent to which individuals are considered representative (prototypical) of the group was positively and significantly related to advice seeking $(r=0.35$, $p<0.001)$. The strength of direct cooperation ties is also a strong basis for advice seeking $(r=0.77, p<0.001)$.

Structural equivalence and dyadic perceptions of common group membership did not appear to be closely aligned. Perceived common group membership and being structurally equivalent were only moderately correlated $(r=0.26, p<0.001)$. Of the ties reflecting common perceived group membership or structural equivalence, only $29 \%$ had both properties in common (Jaccard coefficient).

There were no significant correlations between status variables, or between status and identification variables. Of the status variables, only tenure showed a small but significant correlation to prototypicality $(r=0.12, p<0.01)$. Those that have long tenure in the organization are somewhat more likely to be viewed as typical of their work group. It appears unlikely that prototypicality is simply a proxy for high status, given the low level of association between status variables and prototypicality.

\section{Regression models}

Table 4 gives the results of the regression analysis for advice seeking within the organization. In models 1-6, variables were regressed on advice seeking across the entire organizational network. Status characteristics and identification variables were entered in models 1 and 2, and showed little effect on advice seeking $\left(R^{2}=0.04, p<0.001\right)$. Only tenure $(\beta=0.09, p<0.05)$ and male $(\beta=0.07, p<0.05)$ were significant predictors of advice seeking.

Prototypicality was entered in model 3 resulting in a substantial increase in variance explained to $14 \%$. Prototypicality had a relatively large and significant coefficient $(\beta=0.32, p<0.001)$ while the status variables became non-significant. Prototypicality was hypothesized to predict advice seeking within groups (H5); however, somewhat unexpectedly, it predicted advice across the entire network. Individuals going outside their perceived work group for advice tended to favour those that were prototypical of their respective groups over those having high status.

The group and structural equivalence variables were added in models 4-6. Monadic assignment is initially significant in model 4 ( $\beta=0.16, p<0.001)$; however, adding dyadic perceptions of group membership in model 5 renders monadic assignment non-significant. Consistent with $\mathrm{H} 1$, the additional information contained in a respondent's assessment of whether another individual is in the same group was relevant in predicting advice seeking. In model 6 , only three variables remain significant predictors of advice seeking: perceiving the other to be prototypical ( $\beta=0.28, p<0.001$ ); dyadic perception of common group membership $(\beta=0.12, p<0.001)$; and being structurally equivalent $(\beta=0.28, p<0.001)$. Consistent with $\mathrm{H} 2$ and $\mathrm{H} 3$, individuals tend to seek advice from structural equivalents and from those they perceive to be in the same group.

\section{Inside groups/blocks}

In order to assess the effects of independent variables on advice seeking within groups and structurally equivalent blocks, the data were partitioned into 'inside group' and

Table 3 Correlations (quadratic assignment procedure) for network variables

\begin{tabular}{llllll}
\hline & & 1 & 2 & 3 & 4 \\
\hline 1 & Monadic assignment & & & & \\
2 & Dyadic perception & $0.64 * * *$ & & & \\
3 & Structurally equivalent & $0.17^{* * *}$ & $0.26^{* * *}$ & & \\
4 & Prototypical & 0.01 & $0.09 * * *$ & $0.10^{* * *}$ & $0.29 * * *$ \\
5 & Cooperation & $0.19^{* * *}$ & $0.25^{* * *}$ & $0.41^{* * *}$ & $0.35^{* * *}$ \\
6 & Advice seeking & $0.15^{* * *}$ & $0.25^{* * *}$ & $0.35^{* * *}$ & $0.77^{* * *}$ \\
\hline
\end{tabular}

$* * * p<0.001$. Pearson coefficients. Significance based on 5000 permutations. 
Table 4 Predicting advice seeking: MROAP regression results

\begin{tabular}{|c|c|c|c|c|c|c|c|c|}
\hline \multirow[b]{2}{*}{ Variable } & \multicolumn{6}{|c|}{ Network } & \multirow{2}{*}{$\frac{\text { Inside group }}{7}$} & \multirow{2}{*}{$\frac{\text { Inside block }}{8}$} \\
\hline & 1 & 2 & 3 & 4 & 5 & 6 & & \\
\hline \multicolumn{9}{|l|}{ Advice seeking (DV) } \\
\hline Seniority & 0.03 & 0.04 & 0.04 & 0.02 & 0.03 & 0.04 & 0.04 & $0.08 *$ \\
\hline Tenure & $0.09 *$ & $0.09 *$ & 0.05 & 0.06 & 0.06 & 0.07 & $0.08 * * *$ & $0.10 * * *$ \\
\hline Male & $0.08 *$ & $0.07 *$ & 0.06 & 0.05 & 0.05 & 0.05 & 0 & $0.11 * *$ \\
\hline Affective identification & & -0.01 & -0.02 & -0.04 & -0.05 & -0.02 & -0.01 & -0.05 \\
\hline Commitment & & 0.10 & 0.08 & 0.10 & 0.10 & 0.07 & $0.07 *$ & $0.23 * * *$ \\
\hline Cognitive identification & & 0.08 & 0.07 & 0.07 & 0.06 & 0.07 & $0.15 * * *$ & $0.11 * * *$ \\
\hline Prototypical & & & $0.32 * * *$ & $0.31 * * *$ & $0.30 * * *$ & $0.28 * * *$ & $0.27 * * *$ & $0.29 * * *$ \\
\hline Monadic assignment & & & & $0.16^{* * *}$ & 0.03 & 0.03 & - & - \\
\hline Dyadic perception & & & & & $0.09 * * *$ & $0.12 * * *$ & - & $0.09 * *$ \\
\hline Structurally equivalent & & & & & & $0.28 * * *$ & $0.21 * * *$ & - \\
\hline $\operatorname{Adj} R^{2}$ & $0.02 * * *$ & $0.04 * * *$ & $0.14^{* * * *}$ & $0.16^{* * *}$ & $0.18^{* * *}$ & $0.25^{* * *}$ & $0.19 * * *$ & $0.23 * * *$ \\
\hline
\end{tabular}

$* p<0.05, * * p<0.01, * * * p<0.001$. Standardized coefficients. Significance based on 5000 permutations.

$\mathrm{DV}$, dependent variable; MRQAP, multiple regression quadratic assignment procedure.

'inside block' subsets. With respect to dyadic perceptions of group membership, inside group consisted of all the relations where a respondent perceived another to be in the same group as themselves. With respect to structural equivalence, inside block consisted of relations defined by individuals belonging to the same structurally equivalent block (i.e. having similar patterns of connection in the cooperation network). In the inside group and block analyses (models 7 and 8), data from status, prototypicality, identification and advice-seeking measures were only included if they described relations inside groups or inside blocks. All other data gathered in the network (i.e. the majority of relations - see Table 2) were ignored. The effect of intersecting block/group memberships was controlled by including dyadic perception as a predictor within structurally equivalent blocks and vice versa.

Consistent with $\mathrm{H} 4$, status characteristics proved relevant to advice seeking within groups. Within perceived work groups tenure is related to advice seeking $(\beta=0.08$, $p<0.001)$. Status characteristics also predicted advice seeking within structurally equivalent blocks. Being senior $(\beta=0.08, \quad p<0.05)$, having long tenure $(\beta=0.10$, $p<0.001)$ and being male $(\beta=0.11, p<0.01)$ all predicted advice seeking from those with similar ties in the cooperation network. Being male and being senior were more important when seeking advice from structural equivalents than ingroup members. Greater reliance on readily identifiable status characteristics when seeking advice outside the perceived work group makes sense, as individuals are unlikely to have accurate knowledge regarding who is structurally equivalent. Status characteristics and prototypicality were not correlated within groups or blocks, again indicating that prototypicality is not a proxy for having high status.
Prototypicality predicted advice seeking within groups ( $\beta=0.27, p<0.001$ ) supporting H5. Prototypicality also predicted advice seeking within structurally equivalent blocks $(\beta=0.29, p<0.001)$. Consistent with H6 and H7, identification with work group predicted advice seeking within groups and structurally equivalent blocks.

Within perceived work groups, cognitive identification $(\beta=0.15, p<0.001)$ and commitment $(\beta=0.07, p<0.05)$ predicted advice seeking. The same dimensions of identification predicted advice seeking within structurally equivalent blocks, but the relationship was stronger for commitment $(r=0.23, p<0.001)$ than cognitive identification $(r=0.11, p<0.01)$. Within blocks defined by similar patterns of cooperation ties, commitment (i.e. group ties, belonging) was the stronger predictor of advice seeking. Within perceived work groups, cognitive aspects of identification (the group comes to mind a lot, the group is important to self-image) were most predictive of advice seeking. Affective identification (positive and negative evaluations) did not predict advice seeking in either groups or structurally equivalent blocks. Individuals evaluated their work groups positively (Table 1), but affective identification was not associated with ingroup advice seeking. The findings are consistent with arguments that positive evaluative attachments to groups may or may not elicit group-based behaviours (Ellemers et al., 1999).

\section{Discussion}

The aim of the present study was to test predictions concerning influence from social network, status characteristics and social identity perspectives in an organizational context. 
Methodological issues of non-independence and heterogeneous perceptions of group structure were addressed by using dyadic measures and SNA. The study was limited in that only one relational question was used to measure each theoretical variable in order to minimize the time demands on staff. Using a single question to measure a theoretical variable is not ideal (Rogers \& Kincaid, 1981; Marsden, 1990), but is acceptable provided the questions refer to clearly defined constructs and care is taken to elicit longterm patterns of interaction rather than single events (e.g. Borgatti \& Cross, 2003). The questionnaire was tested prior to administration to verify that participants' interpretations of the questions matched the intended meaning. Also, although we refer to various 'predictors' of advice seeking in the present study, there is no intention to infer causality.

Not withstanding the limitations, some important conclusions may be drawn from the present study. Relational (dyadic) measures of psychological group membership are technically feasible and allow a network representation, or mapping, of psychological group memberships within an organization. Using relational measures allows the effects of perceived group membership, prototypicality and other social identity variables to be assessed alongside the effects of structured interaction. A relational approach to social identity may therefore be useful in understanding a range of organizational behaviours.

Dyadic measures of group assignment proved more effective than monadic measures in predicting advice seeking where heterogeneous perceptions of work group membership and prototypicality were present (H1). Knowing not only a respondent's self-assigned group, but also who they perceive to be in the same group is informative in understanding work-related advice seeking. The results make sense in terms of the social identity perspective, where individuals sharing group membership should be an important source of information about the social context, and even more so if they are prototypical of the group (Turner, 1991).

The findings also make sense from the structural equivalence perspective, where those with similar network ties should be valid sources of information in an organizational context (Burt, 1987; Galaskiewicz \& Burt, 1991). Sharing the same pattern of cooperation ties was predictive of advice seeking over and above the psychological group membership variables. The relatively strong association between structural equivalence and advice seeking suggests that while individuals may have lacked explicit knowledge of other's cooperation ties, they were aware of others' roles and responsibilities in relation to their own work-related goals. Individuals sought work-related advice from structural equivalents largely irrespective of attachments to particular organizational subgroups. As it turns out, the majority of structurally equivalent ties were between individuals who perceived the other to be in a different work group (58\%).
Structural equivalence and perceptions of common group membership were relatively separate predictors of advice seeking across the organizational network ( $\mathrm{H} 2$ and $\mathrm{H} 3)$.

The importance of prototypicality as a predictor of advice seeking clearly applied not only within perceived work groups, but also within structurally equivalent blocks and across the entire network. Referents' conformity to the group prototype (both ingroup and outgroup) was more important than shared group membership in predicting advice seeking. Individuals appeared to have a reasonably clear concept of the defining features of all groups, not just their self-assigned group. This makes sense from the social identity perspective, where the emergence of a social identity involves the comparison of one's own group against other groups, for example, work group X compared with work group Y within an organization (Turner et al., 1994). A more structurally oriented interpretation might be that when individuals seek advice for structural reasons (i.e. the referent has a relevant organizational role or responsibility), they come to view the advice giver as being representative of their (i.e. the advice giver's) respective group. The results appear consistent with both interpretations, and there appears nothing to preclude both processes occurring simultaneously. The implication for future research in organizations is that the effects of prototypicality need not be associated exclusively with self-assigned groups.

The present findings are broadly consistent with previous evidence that status characteristics and social identity have separate and additive effects on social influence (Kalkhoff \& Barnum, 2000; Oldmeadow et al., 2003). Previous studies compared the effects of status characteristics with the effects of categorical group membership (i.e. whether or not the referent is an ingroup member). In the present study, status characteristics were compared not just with categorical group membership, but also with group prototypicality as a predictor of advice seeking. A more complex association between social identity and status characteristics emerges when prototypicality and network effects are included in the analysis. Comparing the effects across the network, perceptions of group membership, structural equivalence and prototypicality were clearly more important than status as predictors of advice seeking. After structural and group effects were accounted for, status had no effect on advice seeking when the network as a whole was considered. Inside groups and blocks, however, status emerged as a significant predictor of advice seeking (partial support for $\mathrm{H} 4$ and $\mathrm{H} 5$ ).

Inside work groups, tenure predicted advice seeking after controlling for identification, prototypicality and structural equivalence. However, the dominance of prototypicality versus status variables suggests that in work-related contexts competence expectations are more aligned with the defining features of the work group than high status. Also of significance for theory is that the strongest status effects were within structurally equivalent blocks. Status charac- 
teristics were more important where referents' proximity in the work place was defined by shared cooperation ties, rather than categorical ingroup membership. The additional emphasis on status seems reasonable, as structural equivalents are not a group in the psychological sense. A lack of explicit knowledge about who is structurally equivalent may lead to greater reliance on overt status characteristics.

Strength of identification (i.e. psychological attachment) with work groups predicted advice seeking from both ingroup members and structural equivalents (H6 and H7). The effect of identification on advice seeking was restricted to within groups and blocks (i.e. there was no general tendency for high identifiers to seek more advice across the network). The noteworthy implication is that high identifiers consistently favoured a set of individuals (structural equivalents) for advice seeking without explicit knowledge of their network position. Identification with one's work group was therefore associated with seeking advice from a set of referents who were neither members of the psychological ingroup, nor members of a readily observed social category. Broader organizational structures and functions seem relevant here. Some aspects of advice seeking are evidently related to identification and perceptions of group membership. However, the results are also consistent with identification with one's work group arising from advice seeking, or cooperation, mandated by organizational structure and processes.

A group-based explanation for the results cannot be ruled out because there may be group-related motivations for seeking advice from structural equivalents. However, an alternative and perhaps more parsimonious theoretical approach would be to link identification directly with network structure. The co-evolution of networks and identities might follow two paths, one from identity to network mediated by perceptions of group membership, and another from network to identity mediated by structural equivalence. The fact that different dimensions of identification were most strongly associated with advice seeking from structural equivalents and perceived work group members suggests that different processes may be operating in each case. When work group is important to self-definition and comes to mind frequently, people tend to seek advice within their perceived work group. When individuals seek advice from structural equivalents, they also tend to feel committed and bonded to the work group. An important issue for further research is whether networks shift to match identities in organizations, or identities shift to match networks as found by McFarland and Pals (2005) in adolescent networks.

\section{Conclusion}

The finding that structurally equivalent blocks and identitybased work groups are relatively separate structures, with identification predicting advice seeking in both, challenges the notion that an exclusively group psychological or network structural approach can adequately explain organizational behaviour. The implication for research is that behavioural concomitants of identification are not necessarily confined to individuals categorized as being members of the same group and, further, that identification should not be ignored when investigating the effects of network structure on influence and other variables. The results add further impetus to calls for a more unified theoretical approach linking identity and network perspectives. A unified theory not only needs to address the effects of group and networkbased social position on a range of behaviours, but it should also incorporate the effects of perceived conformity to group prototypes. Somewhat surprisingly, group prototypicality was the strongest and most consistent predictor of advice seeking within and across groups and blocks.

The present study differs from most previous work in that the effects of group membership and identification are measured in terms of one individual's behaviour towards another in a realistic social context. The dyadic operationalization of social identity variables is effective in overcoming statistical issues inherent in dealing with connected individuals, although the collection of network data is not without practical and ethical difficulties (Borgatti \& Molina, 2003), and the generalizability of findings from a single organization is debatable (see Snijders, 1998; for a brief discussion). There are, nevertheless, advantages in using SNA techniques. Non-independence and the homogeneity/heterogeneity of groups are incorporated into the analysis, and relatively few participants are needed to collect a substantial and detailed data set. The network approach also allows the investigation of perceived social context and network structure over time, facilitating a detailed examination and comparison of theoretical predictions concerning interpersonal interactions, the emergence of social identities and the evolution of social networks.

\section{Acknowledgements}

We wish to acknowledge the Australian Commonwealth Department of Education Science and Training and the Australian National University for their assistance in providing an Australian Postgraduate Award to Mr Copeland. Our thanks go to the Australian National University School of Psychology for additional funding support for this project. Thanks also to James Schuurmans-Stekhoven, and Alden Klovdahl for their helpful suggestions.

\section{End notes}

1. Although it is possible to affect ingroup identification, in this study, identification was measured. See McGarty (1999) and Turner (1999) for discussion on identification and salience. 
2. Cameron (2004) labelled the identity factors centrality, ingroup affect and ingroup ties. Because 'centrality' and 'ties' are longstanding and frequently used networks terms, cognitive identification, affective identification and commitment are adopted to avoid confusion.

3. Principal components analysis (PCA) with OBLIMIN rotation showed a clear Cognitive Identification factor, but did not distinguish Affective Identification and Commitment items. We suspect the lack of appropriate factor structure for affective and commitment items is due to low statistical power $(N=49)$; however, the scales have acceptable reliability and all items were therefore retained to facilitate comparison with other studies.

\section{References}

Ashforth, B. E. \& Mael, F. (1989). Social identity theory and the organization. Academy of Management Review, 14, 20-39.

Baker, F. \& Hubert, L. (1981). The analysis of social interaction data. Sociological Methods and Research, 9, 339-361.

Berger, J. M., Fisek, H., Norman, R. Z. \& Zelditch, M. (1977). Status Characteristics and Social Interaction: An Expectation States Approach. New York: Elsevier.

Borgatti, S. P. \& Cross, R. (2003). A relational view of information seeking and learning in social networks. Management Science, 49, 432-445.

Borgatti, S. P. \& Everett, M. G. (1992). Notions of position in social network analysis. Sociological Methodology, 22, 1-35.

Borgatti, S. P., Everett, M. G. \& Freeman, L. C. (2002). UCINET 6 for Windows: Software for Social Network Analysis. Harvard: Analytic Technologies.

Borgatti, S. P. \& Molina, J. L. (2003). Ethical and strategic issues in organizational social network analysis. Journal of Applied Behavioural Science, 39, 337-349.

Brieger, R. L. (1976). Career attributes and network structure: A blockmodel study of a biomedical research specialty. American Sociological Review, 41, 117-135.

Burke, P. J. \& Stets, J. E. (1999). Trust and commitment through self-verification. Social Psychology Quarterly, 62, 347-360.

Burt, R. S. (1976). Positions in networks. Social Forces, 55, 93-122.

Burt, R. S. (1987). Social contagion and innovation: Cohesion versus structural equivalence. American Journal of Sociology, 92, 1287-1335.

Cameron, J. E. (2004). A three-factor model of social identity. Self and Identity, 3, 239-262.

Cornelissen, J. P., Haslam, S. A. \& Balmer, J. M. T. (2007). Social identity, organizational identity and corporate identity: Towards an integrated understanding of processes, patternings and products. British Journal of Management, 18, 1-16.

Deaux, K. \& Martin, D. (2003). Interpersonal networks and social categories: Specifying levels of context in identity processes. Social Psychology Quarterly, 66, 101-117.

Dutton, J. E., Dukerich, J. M. \& Harquail, C. V. (1994). Organizational images and member identification. Administrative Science Quarterly, 39, 239-263.
Ellemers, N., Kortekaas, P. \& Ouwerkerk, J. (1999). Selfcategorization, commitment to the group and social self esteem as related but distinct aspects of social identity. European Journal of Social Psychology, 28, 371-398.

Feld, S. L. (1981). The focused organization of social ties. American Journal of Sociology, 86, 1015-1035.

Ferrin, D. L., Dirks, K. T. \& Shah, P. P. (2004). Direct and indirect effects of third-party relationships in interpersonal trust. Journal of Applied Psychology, 91, 870-883.

Fielding, K. S. \& Hogg, M. A. (1997). Social identity, selfcategorization, and leadership: A field study of small interactive groups. Group Dynamics: Theory, Research, and Practice, 1, $39-51$.

Friedkin, N. (1984). Structural cohesion and equivalence as explanations of social homogeneity. Sociological Methods and Research, 12, 235-261.

Friedkin, N. (1993). Structural bases of interpersonal influence in groups: A longitudinal case study. American Sociological Review, 58, 861-872.

Friedkin, N. (2004). Social cohesion. Annual Review of Sociology, 30, 409-425.

Galaskiewicz, J. \& Burt, R. S. (1991). Interorganizational contagion in corporate philanthropy. Administrative Science Quarterly, 36, 88-105.

Haslam, S. A. (2001). Psychology in Organizations: The Social Identity Approach. Thousand Oaks, CA: Sage Publications.

Haslam, S. A., Eggins, R. A. \& Reynolds, K. J. (2003). The ASPIRe model: Actualizing Social and Personal Identity Resources to enhance organizational outcomes. Journal of Occupational and Organizational Psychology, 76, 83113.

Haslam, S. A. \& Ellemers, N. (2005). Social identity in industrial and organizational psychology: Concepts, controversies and contributions. In: G. P. Hodgkinson, ed. International Review of Industrial and Organizational Psychology, Vol. 20, pp. 39-118. Chichester: Wiley.

Haslam, S. A. \& McGarty, C. (2001). A 100 years of certitude? Social psychology, the experimental method and the management of scientific uncertainty. British Journal of Social Psychology, 40, 1-21.

Haslam, S. A., Turner, J. C., Oakes, P. J., McGarty, C. \& Reynolds, K. J. (1998). The group as a basis for emergent stereotype consensus. European Review of Social Psychology, 8, 203-239.

Hinkle, S., Taylor, L. A., Fox-Cardamone, D. L. \& Crook, K. F. (1989). Intragroup identification and intergroup differentiation: A multicomponent approach. British Journal of Social Psychology, 28, 305-317.

Hogg, M. A. \& Terry, D. J. (2000). Social identity and selfcategorization processes in organizational contexts. Academy of Management Review, 25, 121-140.

Ibarra, H. \& Andrews, S. B. (1993). Power, social influence, and sense making: Effects of network centrality and proximity on employee perceptions. Administrative Science Quarterly, 38, 277-303.

Jackson, J. W. (2002). Intergroup attitudes as a function of different dimensions of group identification and perceived intergroup conflict. Self and Identity, 1, 11-33. 
Kalkhoff, W. \& Barnum, C. (2000). The effects of statusorganizing and social identity processes on patterns of social influence. Social Psychology Quarterly, 63, 95-115.

Katz, N., Lazer, D., Arrow, H. \& Contractor, N. (2004). Network theory and small groups. Small Groups Research, 35, $307-$ 332.

Kenny, D. A., Mannetti, L., Pierro, A., Livi, S. \& Kashy, D. A. (2002). The statistical analysis of data from small groups. Journal of Personality and Social Psychology, 83, 126137.

van Knippenberg, D. \& van Schie, E. C. M. (2000). Foci and correlates of organizational identification. Journal of Occupational and Organizational Psychology, 73, 137-147.

Krackhardt, D. (1988). Predicting with social networks: Nonparametric multiple regression analysis of dyadic data. Social Networks, 10, 359-382.

Lorrain, F. \& White, H. C. (1971). Structural equivalence of individuals in social networks. Journal of Mathematical Sociology, 1, 489-480.

McCall, G. J. \& Simmons, J. L. (1966). Identities and Interactions. New York: Free Press.

McFarland, D. \& Pals, H. (2005). Motives and contexts for identity change: A case for network effects. Social Psychology Quarterly, 68, 289-315.

McGarty, C. (1999). Categorization in Social Psychology. London: Sage.

McGarty, C. \& Smithson, M. (2005). Independence and nonindependence: A simple method for comparing groups using multiple measures and the binomial test. European Journal of Social Psychology, 35, 171-180.

Marsden, P. V. (1990). Network data and measurement. Annual Review of Sociology, 16, 435-463.

Monge, P. R. \& Contractor, N. S. (2003). Theories of Communication Networks. New York: Oxford University Press.

Morgan, D. L. \& Schwalbe, M. L. (1990). Mind and self in society: Linking social structure and social cognition. Social Psychology Quarterly, 52, 148-164.

Oakes, P. J., Haslam, S. A., Morrison, B. \& Grace, D. (1995). Becoming an ingroup: Re-examining the impact of familiarity on perceptions of group homogeneity. Social Psychology Quarterly, 58, 52-61.

Oldmeadow, J. A., Platow, M. J., Foddy, M. \& Anderson, D. (2003). Self-categorization, status, and social influence. Social Psychology Quarterly, 66, 138-152.

Pattison, P. E. (1994). Social cognition in context: Some applications of social network analysis. In: S. Wasserman \& J. Galaskiewicz, eds. Advances in Social Network Analysis in the Social and Behavioural Sciences, pp. 79-109. Newbury Park, CA: Sage.

Reichers, A. E. (1985). A review and reconceptualization of organizational commitment. Academy of Management Review, 10, 465-476.

Rice, R. E. (1993). Using network concepts to clarify sources and mechanisms of social influence. In: G. Barnett \& W. Richards Jr, eds. Advances in Communication Network Analysis, pp. 43-52. Norwood, NJ: Ablex.

Ridgeway, C. L. (2001). Gender, status and leadership. Journal of Social Issues, 57, 637-655.
Ridgeway, C. L. \& Walker, H. A. (1995). Status structures. In: K. S. Cook, G. A. Fine \& J. S. House, eds. Sociological Perspectives on Social Psychology, pp. 281-310. Boston, MA: Allan and Bacon.

Rogers, E. M. \& Kincaid, D. L. (1981). Communication Networks: Toward a New Paradigm for Research. New York: Free Press.

Sailer, L. D. (1978). Structural equivalence: Meaning and definition, computation and application. Social Networks, 1, 73-90.

Shah, P. P. (1998). Who are employee's social referents? Using a network perspective to determine referent others. Academy of Management Journal, 41, 249-268.

Snijders, T. A. B. (1998). Methodological issues in studying effects of networks in organizations. Computational and Mathematical Organizational Theory, 4, 205-215.

Sparrowe, R. T. \& Liden, R. C. (2005). Two routes to influence: Integrating leader-member exchange and social network perspectives. Administrative Science Quarterly, 50, 505-535.

Stets, J. E. \& Burke, P. J. (2000). Identity theory and social identity theory. Social Psychology Quarterly, 63, 224-237.

Stryker, S. (1980). Symbolic Interactionism: A Social Structural Version. Menlo Park: Cummings.

Stryker, S. \& Serpe, R. T. (1982). Commitment, identity salience, and role behaviour: A theory and research example. In: W. Ickes \& E. S. Knowles, eds. Personality, Roles, and Social Behaviour, pp. 199-218. New York: Springer-Verlag.

Tajfel, H. (1972). La catégorisation sociale (Social categorization). In: S. Moscovici, ed. Introduction à la Psychologie Sociale, pp. 272-302. Paris: Larouse.

Totterdell, P., Wall, T., Holman, D., Diamond, H. \& Epitropaki, O. (2004). Affect network: A structural analysis of the relationship between work ties and job-related affect. Journal of Applied Psychology, 89, 854-867.

Tsai, W. \& Kilduff, M. (2003). Social Networks and Organizations. London: Sage.

Turner, J. C. (1982). Towards a cognitive redefinition of the social group. In: H. Tajfel, ed. Social Identity and Intergroup Relations, pp. 15-40. Cambridge: Cambridge University Press.

Turner, J. C. (1991). Social Influence. Milton Keynes: Open University Press.

Turner, J. C. (1999). Current issues in research on social identity and self-categorization theories. In: N. Ellemers, R. Spears \& B. Doosje, eds. Social Identity: Context, Commitment, Content, pp. 6-34. Oxford: Blackwell.

Turner, J. C. \& Haslam, A. (2000). Social identity, organizations, and leadership. In: M. E. Turner, ed. Groups at Work: Advances in Theory and Research, pp. 25-65. Hillsdale, NJ: Erlbaum.

Turner, J. C., Hogg, M. A., Oakes, P. J., Reicher, S. D. \& Wetherell, M. S. (1987). Rediscovering the Social Group: A SelfCategorization Theory. Oxford: Basil Blackwell.

Turner, J. C., Oakes, P. J., Haslam, S. A. \& McGarty, C. M. (1994). Self and collective: Cognition and social context. Personality and Social Psychology Bulletin, 20, 454-463.

Turner, J. C. \& Reynolds, K. J. (2001). The social identity perspective in intergroup relations: Theories, themes and controversies. In: R. Brown \& S. Gaertner, eds. Handbook of Social Psychology: Vol. 4: Intergroup Processes, pp. 133-152. Oxford: Blackwell. 
Tyler, T. R. \& Blader, S. (2000). Co-Operation in Groups: Procedural Justice, Social Identity and Behavioural Engagement. Philadelphia, PA: Psychology Press.

Wasserman, S. \& Faust, K. (1994). Social Network Analysis: Methods and Applications. Cambridge: Cambridge University Press.

\section{Appendix I: Twelve identity questions (Cameron, 2004)}

Identity questions were asked as follows.

In relation to the group you have just chosen (their own group selected in the previous question), please answer the following questions by circling the appropriate number using the following rating scale $(1=$ strongly disagree, $6=$ strongly agree).

\section{Identification items}

\section{Affective identification (ingroup affect)}

In general, I am glad to be a member of this group. I often regret that I am a member of this group.
I don't feel good about being a member of this group. Generally, I feel good when I think about myself as a member of this group.

\section{Commitment (ingroup ties)}

I have a lot in common with other people in this group.

I feel strong ties to other people in this group.

I find it difficult to form a bond with other people in this group.

I don't feel a sense of being 'connected' with other people in this group.

\section{Centrality}

I often think about the fact that I am a member of this group.

Overall, being a member of this group has very little to do with how I feel about myself.

In general, being a member of this group is an important part of my self-image.

The fact that I am a member of this group rarely enters my mind. 